\title{
OPÇŌES REATIVAS DO ESTUDANTE DE ENFERMAGEM FRENTE AO BANHO TERAPËUTICO DO GRANDE QUEIMADO
}

\author{
Maria Aparecida de Luca Nascimento ${ }^{1}$
}

NASCIMENTO, M. A. L. Opções reativas do estudante de enfermagem frente ao banho terapêutico do grande queimado. Rev. Bras. Enf., Brasília, 39(2/3): 51-54, abr./set. 1986.

\begin{abstract}
RESUMO. Trata-se de pesquisa exploratória junto a estudantes de enfermagem, diante da técnica de balneoterapia do grande queimado, considerando a necessidade da mesma, assim como a síndrome dolorosa à qual este tipo de paciente é submetido, quando da aplicação desta técnica. Os resultados foram obtidos através de dois questionários: o primeiro, aplicado aos estudantes antes do início do ensino clínico onde a referida técnica seria executada; o segundo, após o término do mesmo. Os estudantes foram observados, durante a execução da balneoterapia, e as impressões foram colhidas pelo observador através de uma "folha de observação". Concluiu-se que os fatores que levam os estudantes a não optarem por trabalhar prestando assistência ao grande queimado, executando a técnica de balneoterapia, não estão diretamente relacionados à sua formação profissional e, sim, a fatores inerentes a eles próprios.
\end{abstract}

\begin{abstract}
Explanatory search near to ward students according to the therapeutic bath technic of the intensely burned person, considering its necessity, so as, the painful syndrome to which this kind of patient is subjected when this technic is imputed. The results were taken from two questionnaires: the first one was applied to the students before the clinical teaching, where the related technic would be performed; the second one, after its conclusion. The students were observed during the therapeutic bath execution and the remarks were collected by the observer on a sheet of observation. It was determined that the elements which lead the students to avoid helping the intensely burned person by the therapeutic bath execution are not straightly related to their professional formation but to their inherent factors.
\end{abstract}

\section{INTRODUÇÃO}

Ao enfocar-se o banho terapêutico do grande queimado, enquanto uma assistência de enfermagem a ser prestada, tem-se que o ato de assistir, na sua mais ampla acepção, oferece, a quem se propõe fazêlo, toda uma gama de situações as mais complexas, visto que o ser humano é um ser individualizado no qual o seu todo é mais que a soma de suas partes.

Desta forma, seria pretensioso, a esta altura, tomar-se posição diante de situações inerentes à assistência, mormente em se tratando especificamente de um paciente altamente complexo na sua estrutura biopsicossocial, que é o grande queimado. No entanto, referenciando BELAND 3 , tem-se que a assistência de enfermagem prestada ao paciente grande queimado, sendo um tratamento doloroso, requer do profissional, além de conhecimentos inerentes às necessidades a serem atendidas, tolerância ao dispensá-los. Ainda BELAND ${ }^{3}$, referenciando DAVID e PENDLETON, diz que a tolerância da enfermeira com o paciente queimado advém de um processo de empatia, a partir do qual as enfermeiras se colocam no lugar dos pacientes imaginando o seu sof rimento.

Segundo as autoras supracitadas, em trabalho no qual descrevem a aceitação do papel do paciente por ele mesmo, a tolerância da enfermeira para com o paciente queimado é desejável não só durante a sua fase aguda, como também durante o período no qual o paciente, superando esta fase, passa a apresentar sinais de regressão, choramingando, permitindo e/ou solicitando que as atividades, as quais ele poderia desempenhar sozinho, sejam ainda desenvolvidas pela enfermeira.

Esta empatia do profissional, desejável durante $\mathrm{o}$ atendimento às necessidades do paciente queimado, sendo uma atitude diretamente ligada às características pessoais, pode não estar implicitamente ligada à educação profissional. Porém, o conhecimento dos re-

1. Professor Assistente do Departamento de Enfermagem Materno-Infantil do Curso de Enfermagem do Centro de Ciências Biológicas e da Saúde da UNI-RIO. 
cursos disponiveis (técnicos e materiais) quando da realização deste atendimento, assim como das possíveis reações e sintomatologias relativas a cada paciente, dão ao estudante de enfermagem subsídios para que, segundo BEANLANDS 2 , ele possa se mostrar, se não tão seguro durante o seu desempenho, pelo menos não tão suscetível às agressões de todo o cuidado que, ao ser prestado, provoca ansiedade e dor.

Considerando esta suscetibilidade às agressões vivenciadas pelo profissional durante o exercício de suas atividades - uma vez que o tratamento agride tanto a quem o pratica quanto àquele que é submetido -, tem-se que o tratamento do grande queimado à base de balneoterapia, sendo desenvolvido basicamente pela equipe de enfermagem, é um cuidado que, ao ser prestado, exacerba a síndrome dolorosa a partir da mais simples manipulação do paciente.

O tratamento, então, passa a ser fonte de dor, a partir do qual ambas as partes, enfermeiro e paciente, se vêm interagindo, e ambos suscetíveis às agressões inerentes ao tratamento.

É sobre este profissional, considerando o enfermeiro, que repousa toda uma expectativa sócio-profissional, e é a partir da sua formação técnico-científica durante o seu ensino clínico, onde as situações são observadas in loco -, que se lançam as premissas básicas para uma futura opção de sua atuação profissional.

Tendo em vista o aluno de enfermagem, observa-se que, não obstante toda a novidade existente em torno do tratamento de queimados propriamente dito, a técnica de balneoterapia exclusivamente, sendo uma técnica aplicada durante este tratamento, guarda também, em seus limites, variáveis de comportamento, relacionadas aos aspectos acima descritos. Estas variáveis dizem respeito não só ao paciente, mas também ao estudante de enfermagem, mormente em se tratando de uma técnica que é abordada durante os últimos períodos de ensino clínico.

Considerando que o estudante, ao cursar a Habilitação Médico-Cirúrgica, já possui o Tronco Profissional Comum completo, as situações que até então não haviam sido enfrentadas durante os períodos anteriores podem ter representatividade na vida profissional futura deste estudante.

A expectativa e/ou ansiedade próprios do recémgraduado, frente às técnicas específicas, foram estudadas por ALHADEFF ${ }^{1}$. Em um dos pontos do referido estudo, a autora enfatiza que a proficiência é desenvolvida a partir do simples fazer e repetir várias vezes uma mesma técnica.

Sob este aspecto, vê-se que a abordagem do banho terapêutico do grande queimado, sendo feita durante o Curso de Habilitação em Médico-Cirúrgica, propicia não só a mobilização do estudante frente a uma técnica até então não estudada, como também restringe o conhecimento desta técnica aos alunos de Habilitação Médico-Cirúrgica.

A técnica da balneoterapia do grande queimado é mostrada ao estudante somente durante o ensino clínico, porque uma série de fatores colaboram no sentido de não permitir a sua prática a nível de laboratório, pela própria falta de estrutura física, além da necessária presença do paciente grande queimado. Desta forma, o estudante toma conhecimento da re- ferida técnica sob o impacto de dois fatores: o aspecto do cliente em foco com suas implicações e o set or destinado a este tipo de tratamento.

BELAND $^{3}$, referenciando em seu estudo uma revista especializada, diz que "o êxito de um tratamento de queimados depende de instalações específicas". Baseados nesta afirmação, sem considerar-se os aspectos inerentes a este ou àquele tipo de tratamento dispensado ao queimado, tem-se que a unidade de tratamento de queimados é uma unidade previamente estruturada para este fim. Tal estrutura, visando atender às necessidades do paciente, reúne pacientes afetados pelo mesmo problema em um mesmo espaço físico, permitindo a racionalização do seu atendimento.

Ao enfocar-se o tratamento através do curativo exposto ou aberto, que se segue à balneoterapia, surge a necessidade de se preservar o paciente de contaminação ambiental externa, através de um ambiente fe chado, por ser este um tipo de paciente altamente propenso à infecção. Mediante tais aspectos, o ambiente fechado, inclusive sob a ótica do espaço físico necessário ao tratamento balneoterápico, restringe o referido tratamento a nivel de especialidade. No entanto, a técnica da balneoterapia tem sua aplicação também a nível emergencial, considerando-se que as queimaduras por agentes químicos requerem de imediato a remoção deste agente, a partir da qual haverá uma diminuição no processo de aprofundamento da lesão.

Apesar do alto grau de complexidade do tratamento dispensado ao queimado, mormente aquele calcado em limpeza, remoção de crostas e evolução das lesões, a partir do qual as diretrizes do tratamento são lançadas, observa-se: o paciente queimado, mediante as próprias circunstâncias nas quais ocorre o seu acometimento (tentativa de suicídio, tentativa de homicidio e acidente), é potencialmente um paciente a nivel de emergência.

Os aspectos mencionados acima e as suas devidas implicações afetam seres humanos, que como tal vivem, agem e reagem num contínuo convívio. Através destes seres, operacionalizou-se este estudo, que visa com seus resultados o aspecto humanitário do convívio enfermeiro-paciente.

\section{FORMULAÇÃO DO PROBLEMA}

Tendo em vista que o referido estudo diz respeito, de uma forma tangencial, à educação, já que o mesmo se refere a estudantes, considera-se de vital importância um breve preâmbulo no que tange à política educacional.

Partindo-se da premissa de que a política educacional visa o alcance de objetivos, e que a mesma é um amplo processo, citando $\mathrm{FAVERO}^{4}$, vemos que este processo consiste em:

- Harmonizar, na maior parte das vezes, os objetivos da educação a partir dos objetivos mais gerais.

- Assegurar a concordância dos objetivos da educação com objetivos relativos a outros setores de atividade nacional.

Sendo a educação um processo dinâmico e contestável, já que a mesma diz respeito a idéias, atitu- 
des e mudança de comportamento, obtém-se por dedução que tão mutáveis serão os objetivos educacionais quantos forem os objetivos gerais da sociedade, de forma que os objetivos da educação sejam coerentes com o momento social, sendo desejável haver nesta coerência uma extensão de penetração para atingimento de outros setores, além daquele previamente visado.

Sendo a educação um processo dinâmico de interação, o professor não só dá como recebe ensinamentos, assim como o estudante não só recebe como doa estes mesmos ensinamentos.

Para o estudante são dirigidos os objetivos da educação e sendo ele parte deste processo de interação, da mesma forma age e reage, observa e é observado. A sua percepção de um fenômeno, durante o ensino deste, é tão importante quanto a de seus professores, porque é através dele, futuro profissional, que serão operacionalizados os ensinamentos advindos deste processo.

O profissional em seu campo de ação reproduz e/ou utiliza o que foi adquirido durante o seu período de estudante (sem considerar-se que o período de aprendizagem nunca termina), onde suas bases são lançadas e projetadas para o futuro, sendo o suporte do seu desenvolvimento técnico-cient ífico. Desta forma, quanto melhor a base educacional mais segura é a edificação profissional.

$\mathrm{O}$ ensino superior, a princípio elitizado, tornouse um ensino de massa, trazendo com isto toda uma problemática na qual se vê inserida a dispersão da comunicação dos ensinamentos a serem transmitidos ao estudante, fato que atinge não só o estudante, como também, e em maior grau, ao profissional, fruto desta educação.

Sendo o ensino de enfermagem dirigido para quatro grandes funções, ou seja assistência, administração, ensino e pesquisa, pode-se dizer que em uma só se resume a atividade-fim desta educação, ou seja: o CLIENTE, na sua mais ampla acepção, desde o enfoque profilático ao seu enfoque curativo.

Enfatizando o aspecto curativo do cliente, cada tratamento é prestado de forma específica, resultando daí uma abordagem, no que tange ao ensino, igualmente específica.

Considerando por um lado o cliente, parte de um complexo social enquanto um ser humano, que interage por seu próprio modus vivendi dentro de uma sociedade, e por outro o estudante de enfermagem, parte interativa desta mesma sociedade, sob o enfoque não só de ser humano, como também de profissional operacionalizando os ensinamentos que lhe foram ministrados através da sua formação educacional, chega-se ao âmago da presente pesquisa, ou seja: o estudante de enfermagem, frente a um tratamento específico.

Partindo-se do princípio de que a percepção de um fenômeno é individual, somando-se a esta percepção toda uma bagagem de experiências anteriores, obtem-se uma idéia final deste fenômeno através de um processo somativo. Desta forma, ao enfocar-se o paciente grande queimado, por um lado, e por outro o estudante de enfermagem, interagindo durante um tratamento, ou seja, a balneoterapia, tem-se um fenô- meno, perceptível porém intangível, doloroso porém necessário, e produto de uma percepção individual, acrescida de experiências pessoais. É sobre este fenômeno, visando o estudante de Enfermagem, que serão lançadas as bases para o presente estudo.

Estudantes do Curso de Habilitação em Enfermagem Médico-Cirúrgica, após o término do seu estágio em Centro especializado em Queimados, cujo tratamento é baseado em banho terapêtico, ativ dade esta desenvolvida pelo próprio aluno, relatam unanimemente que estão decididos a não optarem por este tipo de atividade posteriormente, quando do seu futuro exercício profissional, porém não especificam quais os fatores influentes na sua decisão.

As expectativas do estudante frente ao banho terapêutico do grande queimado, assim como todo o processo que se desencadeia durante este atendimento, mormente em se tratando de pacientes propensos à síndrome dolorosa e com a sua auto-imagem afeta$\mathrm{da}$; as perspectivas deste estudante e possíveis implicações e/ou repercussões deste tratamento em seu futuro profissional são o objeto deste estudo.

\section{OBJETIVOS}

O presente estudo visa os seguintes objetivos:

- Identificar as causas que levam o estudante recém egresso de estágio em centro especializado em tratamento de queimados, baseado em banho terapêutico desenvolvido por ele próprio, a não optar por as sistir a esta clientela, desenvolvendo este procedimento técnico, quando do seu futuro exercício profissional.

- Estabelecer uma correlação do conteúdo programático do Curso de Habilitação em Enfermagem Médico-Cirúrgica, com as causas identificadas para a não opção do aluno em assistir o queimado. através do banho terapêutico.

\section{METODOLOGIA}

Este capítulo tem como enfoque principal a discriminação das etapas concernentes ao estudo proposto, tais como:

- Características do estudo

- Características do local da Pesquisa

- População

- Instrumento para coleta de dados.

\section{Características do Estudo}

Este é um estudo do tipo exploratório, tendo como finalidade a identificação das possíveis causas que poderiam contribuir para que os alunos do Curso de Habitação em Enfermagem Médico-Cirúrgica não optassem por trabalhar, quando do seu futuro exercício profissional, junto a pacientes queimados, mormente em se tratando de tratamento à base de balneote rapia.

\section{Características do Local da Pesquisa}

Por se tratar de um estudo exploratório em relação à balneoterapia do grande queimado, tratamento este que requer instalações específicas para o seu desenvolvimento, a presente pesquisa foi desnvolvida em um Centro de Tratamento de Queimados de um hospital da rede federal (previdenciário). 
A escolha do referido setor foi feita não só por ser o único Centro de Tratamento de Queimados de um Hospital com características administrativas públicas dentro do Rio de Janeiro, como também por ser este setor o local de eleição para o desenvolvimento do ensino clínico das turmas de Habilitação em Enfermagem Médico-Cirúrgica, pelas mesmas razões expostas acima.

\section{População}

A população-alvo do estudo em questão referese a um grupo de alunos do Curso de Habilitação em Enfermagem Médico-Cirúrgica de uma Universidade do Rio de Janeiro -8 ? período, constando de vinte e cinco alunos na sua totalidade.

Para que o questionário piloto fosse testado, utilizou-se o grupo do 7\% período do Curso de Graduação em Enfermagem e Obstetrícia desta mesma Universidade.

\section{Instrumento para Coleta de Dados}

$A$ priori foi utilizado um questionário piloto que, ao ser aplicado ao grupo de estudantes do 7 ? período, supracitado, forneceu subsídios para o primeiro instrumento de coleta de dados.

$\mathrm{O}$ primeiro instrumento foi um questionário aplicado à população alvo, antes do início do Ensino Clínico.

O segundo instrumento foi uma folha de observação utilizada no campo de ensino clínico pelo observador, contendo quesitos informativos de cada alu- no individualmente, concernentes ao seu desenvolvimento na técnica de balneoterapia.

$\mathrm{O}$ terceiro instrumento foi um questionário aplicado ao término do ensino clínico à população alvo do referido estudo.

\section{CONCLUSÃO}

Os fatores que levam os estudantes a não optarem por trabalhar prestando assistência ao grande queimado executando a técnica de balneoterapia, não estão diretamente relacionados à sua formação profissional e, sim, a fatores inerentes a eles próprios.

NASCIMENTO, M. A. L. Reactive options of nurse students before the therapeutic bath of the intensely burned person. Rev. Bras. Enf., Brasília, 39(2/3) 51-54, Apr./ Sept., 1986.

\section{REFERÊNCIAS BIBLIOGRÁFICAS}

1. ALHADEFF, G. Anxiety in a new graduate. Amer. $J$. Nurs., New York, 79 (4): 687-8, Apr. 1979.

2. BEANLANDS, H. E. Nurse do you hear me? Can. Nurse, Montreal, 77(7):41-3, Jul./Aug. 1981.

3. BELAND, I. L. \& PASSOS, J. Y. Um paciente com queimaduras. In: Enfermagem clínica; aspectos fisiopatotogicos e psicossociais. São Paulo, EPU, Ed. da Universidade de São Paulo, 1979. v.3, p.21341 .

4. FAVERO, O. Política educacional brasileira - a competência, o poder e as limitações do Ministério da Educação e Cultura. Forum Educ., Rio de Janeiro, 5 (2):29-38, abr./jun. 1981 